incidence of side effects is three times that in children. ${ }^{4}$ Loss of tendon reflexes is the first sign of toxicity, and this is followed by paraesthaesiae, sometimes with distal sensory loss. ${ }^{5}$ If the drug is not stopped distal muscle weakness and wasting occur. Vincristine may damage the autonomic nervous system, producing constipation, a common side effect, or occasionally urinary retention. The degree of toxicity is related to the dose, and the adverse effects usually disappear when the drug is withdrawn.

References to specific laryngeal dysfunction in patients receiving vincristine appear in early reports on the drug. Bohannon et al reported that five out of 35 patients receiving vincristine for late stage resistant leukaemia or lymphoma developed hoarseness. ${ }^{3}$ In that study, however, the doses were higher than are currently acceptable, and with lower doses the danger of recurrent laryngeal nerve damage may have been forgotten. More recently ophthalmoplegia and hoarseness have been mentioned as a complication of vincristine treatment, ${ }^{\circ}$ and recurrent laryngeal nerve damage has been reported in two patients receiving treatment with vinblastine.?

When a patient with a known lymphoma presents with hoarseness it is tempting to assume that this is related to pressura from mediastinal lymphadenopathy. Our experience suggests that this is far less likely than recurrent laryngeal nerve palsy secondary to vinca alkaloid treatment. Two of our patients (cases 2 and 3 ) had shown mediastinal lymphadenopathy at presentation, although it was not visible on chest radiographs when they developed hoarsencss. Furthermore, one patient (case 1) had a right vocal cord palsy. Three of the patients described previously ${ }^{6}$ had a left vocal cord paralysis but the state of the mediastinal lymph nodes was not mentioned.

Like others, ${ }^{7}$ we found that the paralysis in our three patients completely disappeared after the drug was withdrawn. Patients who develop hoarseness during treatment may be thought to have an infection, and consequently the hypopharynx and larynx may not always be examined properly. The knowledge that these drugs are neurotoxic should prompt a more careful laryngeal screening, so that vocal cord paralysis can be detected early and progression to bilateral paralysis, with the danger of respiratory distress, can be prevented.

\section{References}

1 Johnson, I S, et al, Cancer Reseurch, 1963, 23, 1390.

2 Casey, E B, et al, Brain, 1973, 96, 69.

3 Bohannon, R A, Miller, D G, and Diamond, H D, Cancer Research, 1963, 23, 613.

4 Whitelaw, D M, et al, Cancer Chemotherapy Reports, 1963, 30, 13.

5 Lancet, 1973, 1, 980.

6 Holland, J F, et al, Cancer Research, 1973, 33, 1258.

7 Brook, J, and Schreiber, W, Cancer Chemotherapy Reports, 1971, 55, 591.

\title{
Control of blood glucose during labour in diabetic women with combined glucose and low-dose insulin infusion
}

\author{
T E T WEST, C LOWY
}

immature infants as well as in infants of diabetic mothers) is much reduced by delivery after 38 weeks.

Control of the maternal blood glucose concentrations during

\section{Summary}

During 15 labours in diabetic women blood glucose concentrations were controlled with simultaneous infusion of insulin and glucose. The mean insulin infusion rate was between 1 and $2 U / h$. No infant showed evidence of neonatal hypoglycaemia. The procedure is simple to use and may be carried out in any labour ward.

\section{Introduction}

Since insulin treatment first became available the numbers of diabetic women becoming pregnant have increased dramatically. This is due to decreased mortality and increased fertility. Risks to the mother and fetus in diabetic pregnancies have been well established, and it is now established that careful control of blood glucose concentrations (particularly in the last trimester) usually results in the birth of a healthy, normal-weight infant at low risk of developing neonatal hypoglycaemia. The incidence of neonatal respiratory distress syndrome (commoner in

St Thomas's Hospital Medical School, London SE1 7EH

T E T WEST, MD, MRCP, lecturer in medicine

C LOWY, MSC, MRCP, senior lecturer in chemical pathology the use of shorter-acting insulins but give no clear-cut advice the provision of energy requirements. This is important because labour is often prolonged in diabetic mothers. Gastric emptying is delayed in pregnancy and is erratic during labour. This poses the twin problems of correct judgment of insulin dose and preparedness of the mother for general anaesthesia should this be needed-for example, for caesarean section.

We have overcome these problems by modifying the continuous low-dose intravenous insulin infusion technique developed for treating diabetic ketoacidosis ${ }^{1}$ : glucose and insulin are infused simultaneously. We report here the results of using this form of management in 15 labours.

\section{Patients and methods}

Fourteen patients were studied (see table), one of them (case 1) being treated twice during labour after two consecutive successful pregnancies. All except two of the patients were established diabetics receiving long-term insulin treatment. In case 2 the patient had given birth to a large-for-dates baby $(6000 \mathrm{~g})$ eight years previously and was first treated with insulin during the present pregnancy, and the other patient (case 8) first presented with diabetes at 15 weeks' gestation. All patients were closely monitored in the antenatal clinic by an obstetrician and a diabetologist. Blood glucose was carefully controlled. Hospital admission during the earlier stages of pregnancy was advised only for radical changes in insulin treatment or when the blood glucose concentration escaped satisfactory control.

Patients were admitted to hospital one to four weeks before the 
Clinical details of cases studied

\begin{tabular}{|c|c|c|c|c|c|c|c|c|}
\hline \multirow{2}{*}{$\begin{array}{l}\text { Case } \\
\text { No }\end{array}$} & \multirow{2}{*}{$\underset{\text { (years) }}{\text { Age }}$} & \multirow{2}{*}{$\begin{array}{c}\text { Duration of } \\
\text { diabetes } \\
\text { (years) }\end{array}$} & \multirow{2}{*}{$\begin{array}{c}\text { Diabetic } \\
\text { complications }\end{array}$} & \multirow{2}{*}{ Parity } & \multirow{2}{*}{$\begin{array}{l}\text { Duration of } \\
\text { pregnancy } \\
\text { (weeks) }\end{array}$} & \multirow{2}{*}{ Mode of delivery } & \multicolumn{2}{|c|}{ Birth weight of infant } \\
\hline & & & & & & & $\mathbf{g}$ & Percentiles \\
\hline $\begin{array}{rr}1 & \\
2 & \\
3 & \\
4 & \\
5 & \\
6 & \\
7 & \\
8 & \\
9 & \\
10 & \\
11 & \\
12 & \\
13 & \\
14 & \end{array}$ & $\begin{array}{l}22 \\
23 \\
40 \\
32 \\
31 \\
21 \\
22 \\
30 \\
37 \\
27 \\
23 \\
17 \\
18 \\
18 \\
23\end{array}$ & $\begin{array}{r}14 \\
15 \\
1 \\
6 \\
5 \\
10 \\
15 \\
11 \\
<1 \\
19 \\
11 \\
14 \\
8 \\
8 \\
18\end{array}$ & 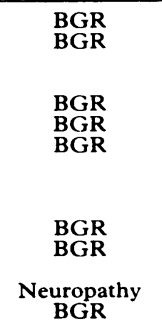 & $\begin{array}{l}0 \\
1 \\
5 \\
1 \\
1 \\
1 \\
0 \\
0 \\
0 \\
1 \\
1 \\
0 \\
0 \\
0 \\
0\end{array}$ & $\begin{array}{l}38 \\
38 \\
39 \\
38 \\
37 \\
38 \\
38 \\
40 \\
28 \\
38 \\
38 \\
38 \\
39 \\
40 \\
39\end{array}$ & $\begin{array}{c}\text { LSCS } \\
\text { Elective LSCS } \\
\text { Elective LSCS } \\
\text { Vaginal } \\
\text { LSCS } \\
\text { Vaginal + forceps } \\
\text { Vaginal + forceps } \\
\text { Vaginal + forceps } \\
\text { Vaginal } \\
\text { LSCS } \\
\text { Elective LSCS } \\
\text { Vaginal + forceps } \\
\text { Vaginal + forceps } \\
\text { LSCS } \\
\text { Elective LSCS }\end{array}$ & $\begin{array}{l}2920 \\
3440 \\
5000 \\
3700 \\
4330 \\
4050 \\
2720 \\
3100 \\
810 \\
3970 \\
2790 \\
4340 \\
3020 \\
2640 \\
3690\end{array}$ & $\begin{array}{r}10-50 \\
50-90 \\
>90 \\
50-90 \\
>90 \\
>90 \\
10-50 \\
10-50 \\
10>90 \\
>0-50 \\
1090 \\
10-50 \\
<10 \\
50-90\end{array}$ \\
\hline
\end{tabular}

BGR = Background retinopathy (dot haemorrhages).

LSCS = Lower segment caesarean section.

planned date of delivery. (Four patients avoided a lengthy stay in hospital by monitoring their own blood glucose concentrations with Dextrostix and a reflectance meter and adjusting their insulin doses accordingly.) After admission insulin dosages were based on preprandial blood glucose concentrations measured three or four times daily two or three times a week.

On the day before delivery insulin was given normally and the patients were fasted after 2200 . Next morning an intravenous cannula was inserted into a forearm vein and glucose (1 litre $5 \%$ dextrose every six hours) and insulin were infused. Actrapid insulin was infused (usually $1-2 \mathrm{U} / \mathrm{h}$ initially) from a syringe pump ${ }^{1}$ : albumin was always added to the insulin infusion mixture. In most patients labour was induced (by rupture of the membranes and a Syntocinon infusion). In four patients caesarean section was elective, and in a further four it was performed because of maternal or fetal distress or failure of labour to progress.

Throughout labour blood glucose concentrations were monitored with Dextrostix and an Eyetone reflectance meter at about hourly intervals. The insulin infusion was adjusted to maintain the blood glucose concentration between 5 and $7 \mathrm{mmol} / 1$ (90 and $125 \mathrm{mg} /$ $100 \mathrm{ml})$.

\section{Results}

Fig 1 shows the individual blood glucose concentrations during 12 hours before and four hours after delivery. There were no significant trends in values among patients who eventually came to caesarean section. The mean insulin infusion rate $( \pm S D)$ during this time was between $1.35+0.89$ and $2.04 \pm 2 \cdot 11 \mathrm{U} / \mathrm{h}$. Figs 2 and 3 show individual results in two patients. In one (case 6, fig 3 ) satisfactory control of blood glucose was never achieved during pregnancy, and the insulin

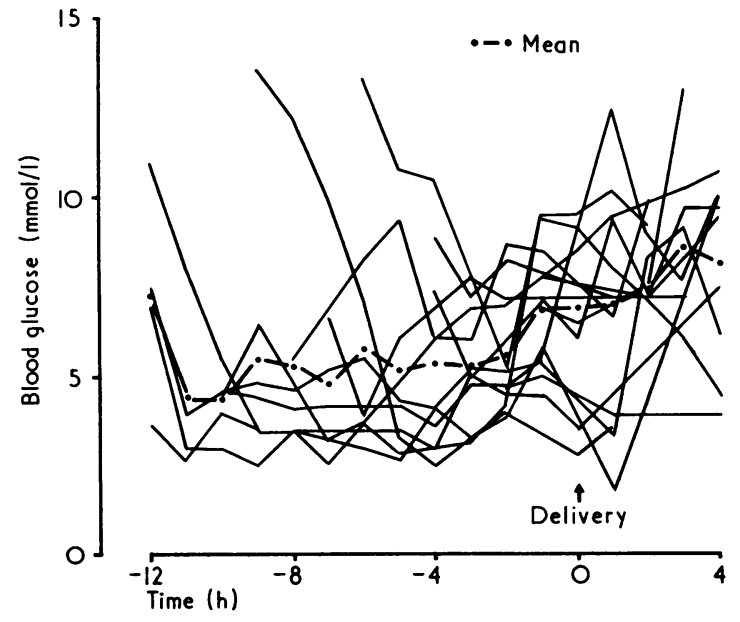

FIG 1-Individual maternal blood glucose concentrations in labour during 12 hours before and four hours after delivery.

Conversion: SI to traditional units-Blood glucose: $1 \mathrm{mmol} / 1 \approx$ $18 \mathrm{mg} / 100 \mathrm{ml}$.

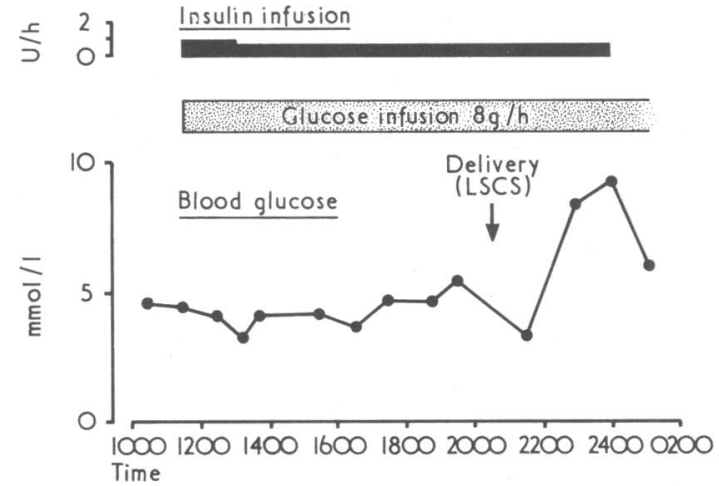

FIG 2-Case 4. Blood glucose concentration during labour, and rates of infusion of insulin and glucose. LSCS = Lower segment caesarean section.

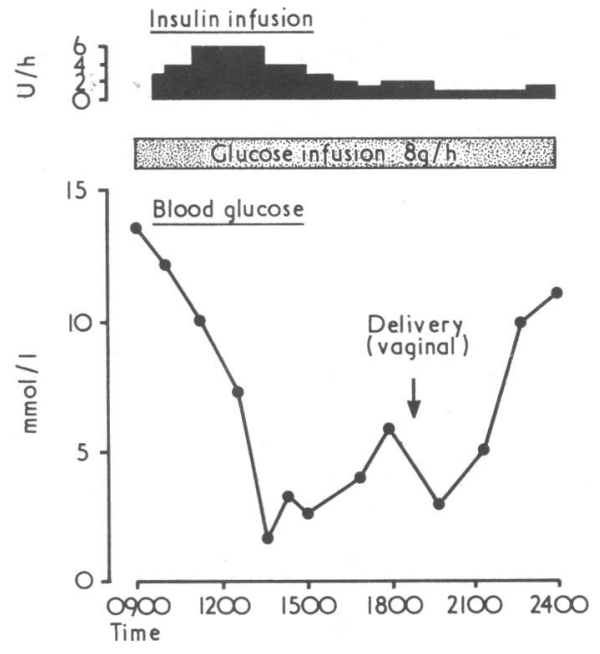

FIG 3-Case 6. Blood glucose concentration during labour, and rates of infusion of insulin and glucose.

infusion rate had to be increased to $6 \mathrm{U} / \mathrm{h}$ during labour. In the other (case 4, fig 2), in whom diabetes had been well controlled during pregnancy, normoglycaemia was maintained during labour with an insulin infusion of less than $1 \mathrm{U} / \mathrm{h}$.

None of the patients developed ketonuria during labour, and none of the infants had biochemical or clinical evidence of neonatal hypoglycaemia. One patient (case 8) went into spontaneous labour at 28 weeks and was delivered of a small infant that died one week later of the respiratory distress syndrome. Two other infants (case 1, first infant; and case 2) showed signs of mild respiratory distress syndrome, which resolved without specific treatment. 


\section{Discussion}

Newborn infants of diabetic mothers are at risk of developing severe hypoglycaemia. ${ }^{2}$ Good control of maternal diabetes during pregnancy increases the fetal survival rate. ${ }^{3}$ Recent reports ${ }^{4}$ support the hypothesis that neonatal hypoglycaemia is due to islet-cell hyperplasia, which in turn may be caused in utero by maternal hyperglycaemia. Since perfect control of maternal blood glucose is aimed at during pregnancy, it is logical to avoid excessive stimulation of fetal insulin secretion immediately before delivery. ${ }^{5}$

The combined infusion of insulin and glucose is a simple way of controlling the maternal blood glucose concentration during labour. It also permits adequate hydration of the mother and prevents starvation ketosis. At the same time the stomach may be kept empty, so that a general anaesthetic can be given without delay.

Infused insulin is cleared extremely rapidly from the plasma, and by means of an insulin infusion the maternal plasma insulin concentration may be readily adjusted to achieve more-constant blood glucose concentrations. Immediately after delivery maternal insulin requirements fall, and the infusion rate of insulin may be lowered accordingly.

Measurement of blood glucose with Dextrostix and the reflectance meter is simple and may be performed by nurses on capillary blood samples obtained by finger-prick at the bedside. The result is available within two minutes and compares favourably with estimations performed by a standard laboratory method. Repeated estimations may be performed without undue discomfort to the patient. (During one premature labour over 100 capillary blood samples were taken in 48 hours.)

Provided that simple rules are observed and equipment is properly standardised, management of diabetes during labour with this method becomes a simple procedure suitable for all obstetric units.

We thank Mr M Cameron for the obstetric care of these patients, and the labour ward staff and Sister Susan Judd and the house physicians of the medical unit for help with management of the infusions.

\section{References}

1 Page, M McB, et al, British Medical fournal, 1974, 2, 687.

2 Farquhar, J W, Archives of Disease in Childhood, 1956, 31, 203.

3 Pedersen, J, and Brandstrup, E, Lancet, 1956, 1, 607.

4 Oakley, N W, Beard, R W, and Turner, R C, British Medical fournal, $1972,1,466$.

5 Milner, R D G, and Hales, C N, British Medical fournal, 1965, 1, 284.

(Accepted 11 March 1977)

\title{
CONDENSED REPORT
}

\section{Prophylactic use of cephazolin against wound sepsis after cholecystectomy}

\author{
C J L STRACHAN, J BLACK, S J A POWIS, T A WATERWORTH, R WISE, A R WILKINSON, \\ D W BURDON, M SEVERN, B MITRA, H NORCOTT
}

British Medical fournal, 1977, 1, 1254-1256

\section{Summary}

A trial of antibiotic prophylaxis with cephazolin against postoperative wound sepsis was carried out on 201 patients undergoing routine cholecystectomy. Wound sepsis occurred in 11 out of 65 controls $(16.9 \%)$, who were not given the drug; two out of 63 patients $(3.2 \%)$

Queen Elizabeth Hospital, Birmingham B15 2TH

C J L STRACHAN, FRCSED, senior lecturer in surgery

$\mathrm{J}$ BLACK, FRCs, lecturer in surgery

B MITRA, MB, BS, registrar in microbiology

General Hospital, Northampton

S J A POWIS, CHM, FRCS, consultant surgeon

M SEVERN, MRCPATH, consultant microbiologist

General Hospital, Birmingham, B4 6NH

A R WILKINSON, FRCS, lecturer in surgery

D W BURDON, MRCPATH, consultant microbiologist

Dudley Road Hospital, Birmingham B18 7QH

R WISE, MRCPATH, consultant microbiologist

North Staffs Royal Infirmary, Stoke-on-Trent

H NORCOTT, FRCS, registrar in surgery

Walsgrave Hospital, Coventry

T A WATERWORTH, FRCS, consultant surgeon given a single dose preoperatively; and four out of 73 patients $(5 \cdot 5 \%)$ given the single preoperative dose plus a five-day course postoperatively. The difference between the controls and patients given the single preoperative dose was significant.

\section{Introduction}

Antibiotic prophylaxis against wound sepsis should rarely be needed during "clean" operations. ${ }^{1}$ Elective procedures on the biliary system, however, are followed by wound infection in $11-20^{\circ} \%$ of cases. ${ }^{2}{ }^{3}$ In some $35-40^{\circ}$, of such cases the organisms cultured from the biliary tract correlate closely with those recovered from the wound, suggesting an endogenous peroperative source. ${ }^{45}$

Parenteral gentamicin ${ }^{6}$ and cephaloridine ${ }^{7}$ have potential for successful prophylaxis, but routine use may encourage the emergence of resistant strains, particularly if instilled into the wound. ${ }^{8}$ A recent semi-synthetic cephalosporin, cephazolin sodium, reaches concentrations in bile several times the serum concentration 90-120 minutes after injection. ${ }^{910}$ In a previous report on non-jaundiced patients with gall-bladder disease high concentrations of this antibiotic were found in the common bile duct one hour after injection. ${ }^{11}{ }^{12}$ In addition, three doses of cephazolin started preoperatively ${ }^{13}$ significantly reduced wound infection. ${ }^{14}$

We report here the results of a single-blind trial comparing wound infection rates in controls, patients given a single dose of cephazolin, and patients receiving a five-day course. 